\title{
ENTRE CONCORDANCIAS, DEBATES Y PARALELOS: FRANCIA EN EL DISCURSO CONCILIADOR DEL DOCTOR AGUSTÍN RIVERA Y SANROMÁN, 1876-1897¹
}

\author{
David Carbajal López \\ Universidad de Guadalajara-Centro Universitario \\ de los Lagos
}

\section{INTRODUCCIÓN}

\begin{abstract}
A lo largo del siglo xIx, el catolicismo se vio obligado a - emprender un diálogo conflictivo con la modernidad. Ésta cuestionaba de manera más o menos directa, ante todo, el predominio de la religión católica como base para la organización de la sociedad, e incluso la antropología en que ésta se basaba. De manera más puntual, la organización eclesiástica, las prácticas religiosas, y en particular algunos de sus actores (las órdenes religiosas, las cofradías) fueron objeto de las críticas de los publicistas liberales. Aunque a lo largo
\end{abstract}

Fecha de recepción: 3 de febrero de 2016 Fecha de aceptación: 20 de abril de 2016

\footnotetext{
1 Agradezco a la maestra Irma Estela Guerra Márquez la gentileza de prestarme algunas de las obras de Rivera citadas en este artículo, y al estudiante de la carrera de Humanidades de la Universidad de Guadalajara-Centro Universitario de los Lagos, Sergio Paúl Carrillo Collazo, su ayuda para procesar las referencias de las Inscripciones de 1869.
} 
de la centuria todo esto llevará a una ruptura, y al ascenso de un catolicismo reaccionario, organizado en torno a la figura del papa, hubo numerosos intentos de conciliación entre la modernidad liberal y la tradición católica, todavía en periodos en que la ruptura parecía ya asentada, como en el último tercio de la centuria. ${ }^{2}$ Desde su natal Lagos, donde residía desde finales de la guerra de Intervención, el doctor Agustín Rivera y Sanromán (1824-1916), longevo clérigo, abogado, historiador, y sobre todo activo publicista en sus años de madurez y vejez, constituye un ejemplo particularmente ilustrativo de esos esfuerzos.

Largo sería exponer aquí una biografía completa de Rivera, bien que habiendo alcanzado el reconocimiento de su larga trayectoria hacia el final de sus días, sus contemporáneos comenzaron ya la difícil labor de ponderar su obra, por lo que no es necesario extendernos al respecto aquí. ${ }^{3} \mathrm{~A}$ nosotros nos interesa en particular por tratarse de un clérigo liberal, publicista como decíamos, autor de al menos 154 obras que van desde hojas sueltas hasta obras eruditas de varios tomos, tocando los más diversos géneros (historia, literatura, filosofía, oratoria sagrada y patriótica, etc.).

${ }^{2}$ La bibliografía es harto extensa, mas para plantear la problemática en lo fundamental podemos remitirnos a las obras de SERRAno, ¿Qué hacer con Dios en la república?; Connaughton, Entre la voz de Dios; García Ugarte, Poder político y religioso. Para el caso francés Boutru, Prêtres et paroisses; Lagrée, Religion et modernité; LalouetTe, La séparation des Églises et de l'État.

3 Ya en vida de Rivera aparecieron los textos de Valverde, "El presbítero Dr. D. Agustín Rivera”, y la biografía de MuÑoz, Rasgos biográficos, y sólo un año después de su muerte, la biografía y bibliografía encargadas por la Academia Mexicana de la Historia: Toro e ÍGuiniz, El Dr. Dn. Agustín Rivera y Sanromán. 
En esos escritos, como cabía esperar, estuvieron presentes autores franceses e incluso querellas que tenían lugar en el seno de la Iglesia galicana, así como la memoria de ciertos pasajes de su historia, como la revolución francesa. Mas acotemos de inmediato que sería excesivo pensar en Rivera como un autor afrancesado: ya lo han notado otros estudiosos de su obra, incluso sus propios contemporáneos; en su obra están sobre todo presente escritores españoles. Fue un intenso lector de Melchor Cano, de Miguel de Cervantes y del padre fray Benito Gerónimo Feijoo. ${ }^{4}$ Más todavía, fue un incansable lector de obras clásicas y recientes, de traducciones y originales de autores italianos y de otros puntos de América y Europa. Lo veremos, sus lecturas francesas fueron muy amplias y se mostró tanto crítico de algunas como seguidor incondicional de otras.

Esas referencias francesas de Rivera no son un asunto menor, pues constituyen un excelente eje para analizar y darle sentido a la dinámica de su extensa obra. En efecto, en su larga trayectoria marcada por el siempre difícil equilibrio entre liberalismo y catolicismo, sus lecturas francesas constituyen inflexiones importantes en un sentido o en otro, hacia el cuestionamiento de la secularización, o al contrario, hacia una toma de postura crítica del ultramontanismo. ${ }^{5}$

\footnotetext{
4 "A cada paso se nota en las obras del Dr. Rivera la decidida predilección que tiene por el benedictino Feyjoo, y por el inmortal Cervantes", decía Valverde, "El presbítero Dr. D. Agustín Rivera". Véase en particular el estudio reciente de Connaughton, "Agustín Rivera, Feijoo y la epopeya nacional mexicana".

${ }^{5}$ Casi sobra decir que el concepto de "secularización", así como las categorías de "ultramontano", "galicano" o "jansenista" están ausentes en las obras de Rivera que citamos aquí, pero justo nos parece que su obra ayuda a repensarlas para el caso mexicano.
} 
En concreto vamos a analizar un corpus muy preciso de obras de Rivera, 11 en total, prácticamente todos folletos publicados en el último tercio del siglo xIX, entre 1869 y 1897. Se trata de una selección en la cual hemos tomado en consideración la presencia de referencias francesas, pero repetimos, además son significativas en el conjunto de su obra. En principio, de su época de catedrático, retomamos las Inscripciones en las paredes del Liceo de Lagos (1869), la cual nos da una idea de la importancia de sus lecturas para su labor docente a inicios de su carrera. Enseguida, el breve tratado escolástico Concordancia de la razón y la fe de 1876, una de las obras más importantes de esa primera etapa, constituye acaso uno de los mejores resúmenes de los planteamientos de la antropología católica de Rivera.

Aunque ya entonces Rivera se introducía en controversias, son sus obras de principios de la década de 1880 las que dan cuenta de una toma de postura más firme, aunque coherente con esas primeras obras. Hay tres folletos que surgen casi de manera simultánea y que dan cuenta de ello: ante todo, el Ensayo sobre la enseñanza de los idiomas latino y griego y de las bellas letras por los clásicos paganos (18811889), texto fundamental en los debates de Rivera contra el ultramontanismo. Éste no puede sino acompañarse del diálogo Los dos estudiosos a lo rancio (1882) y de la Descripción de un cuadro de veinte edificios (1883), en los que además toma postura frente a la moderna literatura francesa.

Sin embargo, el momento más prolífico de Rivera fue la década de 1890. En esos años, ya desde 1889 con la Miscelánea Selecta, pero sobre todo entre 1891 y 1897, nuestro autor recuperó, por una parte, la oratoria sagrada francesa de los siglos XVII y XVIII, en particular las obras de 
Jean-Baptiste Massillon (El Cempazúchil, 1891) y Charles Frey de Neuville (La pobre bumanidad, 1893). Por otro lado, desde la segunda entrega de la Miscelánea selecta (1889), se advierte un tratamiento distinto de los autores radicales franceses. Es en este periodo cuando tuvo un pequeño debate sobre la memoria de la revolución francesa, que motivó sus Tres artículos (1891) y en particular se abrió a la obra de Jean-Jacques Rousseau en su Paralelo de 1894. El último trabajo que hemos seleccionado es El progreso lento y el radical en la destrucción de la esclavitud (1897), que justo nos ayuda a situar a Francia en la mirada histórica de conjunto del doctor Rivera y Sanromán, ya de estos años de madurez de su obra.

En suma, pues, vamos a recorrer dos décadas de la obra de Agustín Rivera y Sanromán, y a partir del eje de la presencia gala, a entrar en el detalle de la construcción de su esfuerzo conciliador, con sus giros y matices a lo largo de su vida.

\section{LIMBO DE LOS ANTIGUOS Y LÍMITE DE LOS MODERNOS:}

ANTROPOLOGÍA Y GRACIA

En 1869, Agustín Rivera y Sanromán era catedrático de historia en los liceos fundados por el padre Miguel Leandro Guerra en Lagos. Como parte de su labor docente, mandó colocar en las paredes del establecimiento una serie de 78 inscripciones con citas de autores, divididas en nueve secciones temáticas. Institución formadora de la élite laguense, motivo de orgullo local, la empresa puede parecernos anecdótica, pero era lo suficientemente importante para que el fundador enviara una copia de las inscripciones a la prensa 
nacional. ${ }^{6}$ Para nuestro tema es de interés constatar que los autores franceses y la lengua estaban presentes pero muy lejos de ser mayoría. Sólo había citas en tres idiomas: español (61), latín (14) y francés (2). El grupo más citado eran los autores clásicos latinos con 24 inscripciones; de hecho, el autor más citado era Cicerón (5 veces), lo cual ya veremos que reviste interés para nuestra problemática. Los clásicos iban seguidos de 14 referencias bíblicas, 15 citas de autores españoles, 10 de novohispanos y mexicanos, y finalmente, sólo 5 de autores franceses. ${ }^{7}$

Cinco citas pues, dos de ellas en su idioma original, pero en realidad se trata de cuatro autores, según su antigüedad: Fenélon, Napoleón Bonaparte, Mme. de Staël y Alexandre Dumas padre. Esto es, un predicador moralista del siglo XviI, un general y conquistador impulsor de un liberalismo autoritario, una dama - la única otra mujer citada en estas inscripciones fue sor Juana Inés de la Cruzliberal moderada o partidaria de la Restauración, ${ }^{8}$ y en fin, un novelista liberal de origen mulato. El perfil de cada autor es ya elocuente de lo que Rivera esperaba recuperar de los autores franceses para la educación de los jóvenes laguenses. Sin embargo, conviene atender a las propias citas: Fenélon, casi paradójicamente, aparece en las secciones de

${ }^{6}$ Concretamente a la Revista Universal, t. V, núm. 1076, 18 de enero de 1871, p. 3.

${ }^{7}$ Los diez restantes incluían tres clásicos griegos, dos padres de la Iglesia oriental, un escolástico medieval de origen italiano, un autor germánico, dos anglosajones y uno italiano.

${ }^{8}$ Cabe decir que Rivera llegó a destacarla en particular por haber escrito "con un nervio de pensamientos varoniles y profundos y en estilo varonil”. Rivera, Ensayo sobre la enseñanza, p. 62. 
"gimnástica" y de "agricultura"; de manera más coherente, la hija de Necker está citada en la de "educación moral" y los otros dos directamente en la de "moral". Dumas aparece en la subsección de "obligaciones para con Dios" y Bonaparte, en la de "obligaciones para consigo mismo".?

En suma, pues, en esos años Rivera estaba lejos de recomendar con amplitud el pensamiento de autores franceses, y sólo extraía de ellos, de manera muy selectiva, pasajes poco controvertidos, más bien técnicos o con enseñanzas morales, desde luego dentro de la moral católica. Era un recuento de inscripciones para la educación de la juventud en un colegio de tradición eclesiástica, y difícilmente hubieran podido caber citas de autores de la Ilustración más radical o de la Revolución. Empero, destaquemos que el clasicismo superaba a los autores bíblicos, problemática que, ya veremos, era también francesa en esta época: la moral, Rivera no sólo la aprendía en los textos específicamente de religión cristiana, y para justificarlo también hizo recurso a esa amplia gama de escritores franceses, en el arco entre la época de Fenélon y la suya, que aprovechó en la Concordancia de 1876.

Tratado de teología elaborado de manera perfectamente escolástica, desde su portada la obra anunciaba que su público eran "los jóvenes estudiantes de la filosofía moral". ${ }^{10}$ Esto es, seguimos en las obras docentes de Rivera, pero ahora pasamos a otro nivel. El objetivo del texto era defender

\footnotetext{
9 Rivera, Inscripciones, pp. 2, 3, 6 y 9.

10 Paradójicamente, a pesar de su importancia, es uno de los textos de Rivera que no tuvo más que una sola edición. El propio Rivera no consideró necesario destacarla cuando su balance de 50 años como escritor, en Rivera, Bodas de oro, p. 13.
} 
una proposición formulada en nota al pie de un artículo anterior, a saber: "La razón natural no estaba enteramente oscurecida entre los paganos, a pesar de sus iniquidades [...] porque estaba impresa en sus almas". ${ }^{11}$ A partir de ahí, Rivera desarrollaba cinco proposiciones sobre los alcances de la razón para el conocimiento de la ley natural, sus límites en cuanto al conocimiento de la revelación, y en consecuencia la condenación o no de los infieles viviendo bajo la ley natural. Por decirlo de manera muy breve y directa, el padre Rivera afirmaba que los infieles no necesariamente se condenaban, tampoco es que pudieran llegar al cielo, pero sí al menos al limbo. ${ }^{12}$ La primera y la última de estas proposiciones eran las más extensamente desarrolladas, pues presentaban exhaustivamente pruebas, objeciones y respuestas. Artículo erudito, contiene al menos 93 citas y referencias explícitas, buena parte de ellas en las 58 notas incluidas al final del texto. ${ }^{13}$

Aunque no se destacaba necesariamente por su gran originalidad, el artículo abordaba un tema fundamental a nivel

11 Rivera, Concordancia de la razón y la fe, p. 1.

12 Rivera, Concordancia de la razón y la fe, pp. 8-15. La firme creencia en el limbo que muestra en este texto no evita que Rivera se muestre crítico de otros lugares de la geografía tradicional del más allá, como de los relatos y descripciones del Purgatorio. Rivera, Ensayo sobre la enseñanza, pp. 325-326. Para este tema Cuchet, Le crépuscule du Purgatoire, pp. 96-114, obra que lamentablemente no trata del limbo.

${ }_{13}$ Algunas de esas referencias en realidad están tomadas por intermedio de otros autores. Aunque a lo largo de sus obras Rivera debió justificar su estilo lleno de citas detalladas, paradójicamente en este caso no siempre hizo mención de esa fuente. Fue el caso sobre todo de un autor que veremos duramente criticado por Rivera en el siguiente apartado: el superior teatino Joaquín Ventura de Ráulica. Ventura, La escuela de los milagros, t. I, pp. 360-361 y Rivera, Concordancia de la razón y la fe, pp. 9 y 21. 
teológico y doctrinal para la definición misma del catolicismo. Además, así fuera de forma marginal, tocaba temas que históricamente habían sido motivo de grandes controversias, al menos desde el siglo xvi, pero que se situaban ahora en el contexto de los debates con la modernidad. En efecto, aunque por momentos parecería un ensayo escrito simplemente por el gusto de tomar la pluma, Rivera escribía para debatir, aunque de forma más bien discreta, con ciertos autores que en algún momento llega a denominar "tradicionalistas". ${ }^{14}$ Tal vez justo por ello era particularmente oportuno utilizar el método escolástico: el autor no trata de criticar a la modernidad, sino a los propios apologistas católicos del siglo XIX, quienes, se entiende al menos del conjunto del texto, caerían a veces en "absurdos" teológicos, incompatibles con la propia tradición del catolicismo.

Es ilustrativo al respecto el cierre de su primera proposición, cuando llega a las pruebas ab absurdo: "Muy censurado es con razón el sistema de que el estado de los hombres primitivos fue el estado salvaje", afirmaba tomando distancia de la antropología de los autores liberales; "pero este otro raro sistema de la insuficiencia de la razón sin la revelación le saca un pie adelante en absurdidad" ${ }^{15} \mathrm{En}$ efecto, se trataba para Rivera de presentar de manera auténtica la antropología clásica del catolicismo: un humanismo moderado, en que el ser humano, a pesar del pecado original, no dejaba de poseer una razón natural capaz incluso de reconocer a Dios y algunos de sus atributos, y sobre todo, de seguir la ley natural. Lo afirmará con mayor claridad en

14 Rivera, Concordancia de la razón y la fe, p. 7.
15 Rivera, Concordancia de la razón y la fe, p. 5. 
su respuesta a la tercera objeción de su primera propuesta: "La diferencia entre el hombre y el bruto consiste en la razón”, si los infieles, por falta de la revelación (cristiana, se sobreentiende), carecieran de ella, se preguntaba, “ ¿es decir que todos los infieles son animales irracionales?, ¿es decir que Platón y Aristóteles fueron como un par de jumentos?”. ${ }^{16}$

Aunque en realidad Santo Tomás de Aquino es citado apenas tres veces en todo el texto, se diría que sigue en buena medida la tradición tomista en el sentido de que la naturaleza es perfeccionada y no destruida por la gracia divina. Esto, empero, no lo encontraremos sino en un texto que veremos más adelante: en una nota al pie de su folleto $L a$ pobre bumanidad (1893), Rivera estimaba necesario grabar con letras de oro "la doctrina de Santo Tomás: 'La gracia sigue el modo de la naturaleza': Gratia sequitur modum naturae. ${ }^{17}$ Volveremos sobre ello más adelante.

Si en la primera proposición Rivera empuña la pluma sin decir con precisión contra quién se dirige, en la última en cambio su objetivo es más preciso: el abogado y apologista católico laico francés Jean-Jacques-Auguste Nicolas, en particular el capítulo XIV de la segunda parte de sus Études Philosophiques sur le Christianisme. La crítica de nuestro autor contrasta con lo que hizo en las primeras páginas de su artículo: si ahí trataba sobre todo de salvar a la razón natural humana, aquí en cambio se trata de no exaltarla en exceso. En ese capítulo, Nicolas se dedica a responder a quienes utilizaban la frase de San Cipriano Extra Ecclesiam nulla salus

${ }^{16}$ Rivera, Concordancia de la razón y la fe, p. 6. Retengamos este problema para lo que vendrá después en sus siguientes debates a propósito del ultramontanismo.

17 Rivera, La pobre humanidad, p. 7. 
para criticar al catolicismo. En un momento de su argumentación llega a la misma problemática de Rivera: la cuestión de quienes no conocieron el catolicismo. El apologista francés lo resuelve afirmando que, por estar en "una ignorancia invencible de la ley evangélica" podían morir "en estado de justicia natural", y que tal había sido una doctrina incontestada en el catolicismo. ${ }^{18}$

La obra de Nicolas data de la década de 1840, pero tuvo varias ediciones a lo largo del siglo. La traducción al español fue hecha en Madrid, a mediados de la década de 1850; Rivera no lo detalla, pero la cita de su artículo sigue precisamente el tenor de la segunda edición de dicha traducción (1854). ${ }^{19}$ Ésta, en cambio, no corresponde de manera literal con la edición francesa de 1852, que no incluye el término "justicia natural" y precisa solamente que se trata de infieles que "ont fidèlement pratiqué tout le bien qui leur était connu". ${ }^{20}$ Sea un error de traducción o un cambio propio de ediciones posteriores, el tema es que el padre Rivera encontraba la afirmación excesiva, pues parecía implicar que incluso herejes, paganos e idólatras podían alcanzar el Cielo. Estaba de acuerdo con el francés en que "no se condenan", pero no en que el catolicismo enseñara que "se salvan", decía directamente. ${ }^{21}$ De ahí la importancia de la geografía del más allá, ausente de la obra de Nicolas en ese punto, y en particular del limbo, que asimismo el autor francés olvida por completo en el capítulo citado: ese lugar intermedio entre cielo, infierno y purgatorio, históricamente más cercano a este

${ }^{18}$ Citado en Rivera, Concordancia de la razón y la fe, pp. 15-16.

19 Nicolás, Estudios filosóficos sobre el cristianismo, t. II, p. 498.

${ }^{20}$ Nicolás, Études philosophiques sur le christianisme, t. III, p. 313.

${ }^{21}$ Rivera, Concordancia de la razón y la fe, p. 16. 
último, ${ }^{22}$ era literalmente el punto más alto que la razón humana podía alcanzar por sí misma. No aparece de manera explícita, pero se entiende que abrirle las puertas del cielo a los antiguos paganos era una complacencia innecesaria con los modernos.

Ahora bien, aparte de discutir a un autor francés, al que sin embargo reconocía como "uno de los primeros apologistas de la religión en el siglo xix y muy benemérito de la Iglesia católica", ${ }^{23}$ Rivera además muestra en este artículo su profundo conocimiento de obras francesas. Sin embargo, como vimos antes, los autores franceses no son los más citados por Rivera. Clasificando las 93 citas y referencias del artículo, en realidad el grupo más amplio lo forman 27 que proceden de textos bíblicos, figurando en primer lugar las Épistolas de San Pablo (13 veces), sobre todo a los Romanos (8 veces). En términos individuales, después de San Pablo vendría San Agustín de Hipona, con diez citas y referencias de un conjunto casi de igual número de obras. Pero tras las citas bíblicas en realidad el conjunto más amplio son los autores franceses y de tradición francesa de los siglos Xvir al XIX, los cuales suman 17 citas y referencias de ocho autores (Charles-René Billuart, Cornelio Alápide, Jean-Baptiste Bouvier, Louis Bourdaloue, Denis-Luc Frayssinous, Jacques-Bénigne Bossuet, Auguste Nicolas y uno anónimo). Excluimos de este conteo a cinco autores medievales (Haymon, Escoto, san Anselmo, san Bernardo de Claraval

22 Para sus orígenes, en síntesis, BASCHET, La civilización feudal, pp. 427441, en especial 437-438.

${ }^{23}$ Rivera, Concordancia de la razón y la fe, p. 16. En la década siguiente nuestro autor se mostrará algo menos amable con los publicistas que criticaba. 
y Santo Tomás de Aquino), con diez referencias entre todos, pero que no pueden encasillarse estrictamente en la categoría de autores específicamente franceses. En cambio, incluimos a Cornelio Alápide, que, aunque de origen neerlandés hizo su obra en una universidad estrechamente vinculada a la tradición francesa, la de Louvain.

Lo que llama ya la atención de este conjunto de obras $\mathrm{y}$ autores es que claramente pueden separarse entre el siglo XVII (Alápide, Bourdaloue y Bossuet) y el XIx (los restantes), pues sólo la obra del dominico Billuart corresponde al xviII. En cuanto a temas se delinean también con claridad tres intereses fundamentales. En primer lugar, la teología: las Institutiones de Bouvier, manual de amplia circulación en la Francia de la época, es la obra más citada de autores franceses; Rivera citó también un manual de teología del Gran Seminario de Saint-Flour y la ya mencionada obra de Billuart, una exposición de la obra de Santo Tomás de Aquino. Además, la Concordancia cita varios comentarios teológicos de Alápide y de Bossuet. Al menos en materias teológicas, se diría que nuestro autor no tenía prejuicio conta los autores galicanos, al menos no tenía prejuicio alguno contra ellos: el jesuita Alápide es excepción, pero lo eran sin duda Bossuet, Billuart y sobre todo Bouvier. Parece ser que Rivera no llegó a saberlo, pero es una obra que incluso fue denunciada ante el Índice de Roma a mediados del siglo y terminaría siendo expurgada en la segunda mitad del mismo. ${ }^{24}$ En segundo lugar, Rivera leía predicadores franceses, jesuitas del siglo XvII como Louis Bourdaloue $-\mathrm{y}$ ya veremos que no fue el único-, y apologistas más recientes como

${ }^{24}$ Aubert, "La géographie ecclésiologique”, pp. 16-17, 22 y 46. 
el Conde de Frayssinous (asimismo autor galicano, cabría acotar), a quien reconoció como "el célebre precursor de Lacordaire en el púlpito de Nuestra Señora". ${ }^{25}$ En fin, en tercer lugar estarían apologistas más modernos y ultramontanos como el propio Auguste Nicolas, quien ya vimos que es objeto de la moderada crítica de Rivera.

Ecléctico, se advierte bien que nuestro autor no apreciaba necesariamente a los apologistas franceses ultramontanos, y podemos ver ya su aprecio, sin hacer muchas distinciones, más bien por los autores del Gran Siglo francés, el xviI (Boussuet, Bourdaloue, agreguemos a Fénelon, citado antes) y los de la primera mitad del XIx (Frayssinous, Bouvier, además de a Mme. de Staël, mencionada más atrás). En Concordancia no tomaba partido en las querellas de la Francia de la época, pero ya desde unos años antes nuestro autor estaba siendo alcanzado por un debate que había dividido a la Iglesia galicana unas décadas, y que lo obligó a mostrarse más combativo frente al ultramontanismo.

PERJUICIOS DE LOS ANTIGUOS Y PREJUICIOS

DE LOS MODERNOS: EDUCACIÓN Y TRADICIÓN

En 1872, Agustín Rivera y Sanromán era capellán de las religiosas capuchinas exclaustradas de Lagos, y vivía además dedicado a su trabajo de escritor. Es por entonces que tomó conocimiento del informe del rector del Seminario de Colima presumiendo de la eliminación de los "clásicos paganos"

${ }^{25}$ Rivera, Concordancia de la razón y la fe, p. 20. Reconocimiento que no le valía al padre Lacordaire ser particularmente citado en los folletos que hemos examinado. 
de la formación que se brindaba en su establecimiento, siguiendo las consignas del abate Jean-Joseph Gaume y del superior general de los teatinos, Joaquín Ventura de Ráulica. Nuestro inquieto autor inició correspondencia con el obispo de León, el doctor y maestro José María de Jesús Díez de Sollano y Dávalos, consultándole sobre el tema. El prelado lo remitió a las obras de Gaume, Le ver rongeur des sociétés modernes ou le paganisme dans l'éducation (1851), así como La Révolution. Recherches historiques sur l'origine et la propagation du mal en Europe, depuis la Renaissance jusqu'à nos jours (1856), conocida en español como Historia de la Revolución, y a la del padre Ventura, El poder político cristiano, que incluía sus sermones de Cuaresma en las Tullerías de 1857, y a la encíclica Inter Multiplices del papa Pío IX. Desde luego, Rivera no se conformó con ello - aunque comenzó a reunir los libros en cuestión-, e inició así una breve correspondencia entre el prelado y el capellán sobre el tema. El obispo presentó de manera muy puntual el motivo de la exclusión de los clásicos paganos; esto es, sus "funestos resultados" que no eran sino la propia revolución francesa, y Rivera, su preocupación justamente por la enseñanza de los colegios jesuitas en particular, formulando ya algunas proposiciones para defender a esos autores antiguos. ${ }^{26}$

Nuestro autor, pues, tomó así conocimiento de la querelle des classiques que, en la década de 1850, tras la promulgación de la ley de libertad de enseñanza, había enfrentado a "ultramontanos" y "galicanos" en el seno de la Iglesia francesa, los primeros apoyando al abate y luego monseñor Gaume, los segundos encabezados por el obispo de Orleáns,

${ }^{26}$ Rivera, Ensayo sobre la enseñanza, pp. 1-11. 
Félix Dupanloup. Tema ya conocido de la historiografía reciente, ${ }^{27}$ no entraremos aquí en los detalles de la querella, sólo es importante tener presente que, si bien monseñor Gaume no obtuvo la reforma de los estudios que esperaba, la Santa Sede tendió a apoyar a los ultramontanos franceses en detrimento de sus rivales. ${ }^{28}$

A lo largo de la década de 1880, nuestro autor publicó en varias entregas su respuesta a la obra de monseñor Gaume y del padre Ventura. Además de publicar de nuevo su correspondencia con el obispo de León, redactó un total de 55 adiciones que formaron un volumen compacto de 376 páginas, titulado Ensayo sobre la enseñanza de los idiomas latino y griego y de las bellas letras por los clásicos paganos. Mas cabe aclararlo, Rivera y Sanromán presentó siempre el debate en que participaba sin asumir la división entre ultramontanos y galicanos: ${ }^{29}$ únicamente habló de "gaumistas"

${ }^{27}$ Moulinet, Les classiques païens, es sin duda la obra reciente más informativa sobre el tema. Un resumen en WENGER, "La querelle des ultramontains"; la contextualización en las luchas de poder internas del catolicismo francés en Hérisson, "Louis Veuillot". Otras luchas de monseñor Gaume en Boutry, Prêtres et paroisses, pp. 169-176 (sobre los cementerios) y 409-410 (sobre la moral). Una nota sobre las repercusiones de Gaume en España en García Jurado, "La Iglesia Católica contra la enseñanza de los clásicos" y un estudio de las redes "gaumistes" en Québec en Brunet, "Les réseaux gaumistes". Para México, si bien no hay, hasta donde sabemos, estudios amplios sobre la difusión de Gaume, véase al menos OrTIz, "El humanismo conservador".

${ }^{28}$ Es cierto, la encíclica Inter Multiplices, que debía cortar la querella "apparemment il donne raison à tout le monde, mais à y regarder des près, on voit que ce sont les thèses des ultramontains qui triomphent", señalaba ya Wenger, "La querelle des ultramontains", p. 844. De hecho, la encíclica marca prácticamente la consagración de los laicos ultramontanos frente a los obispos galicanos. Hérisson, "Louis Veuillot”, pp. 344-345.

${ }^{29}$ Esto no evitó que identificara bien a los actores de la querella, en 
y "antigaumistas", ${ }^{30}$ con lo cual evitaba afrontar la división de proyectos de Iglesia que significaba la querella francesa, definiéndola como un mero punto de disciplina, a pesar de que su propia retórica hacía evidente que había un desacuerdo mucho más fundamental. Además, siempre escribió considerando que la encíclica de 1853, y un breve pontificio posterior (1874, cuya traducción incluyó), eran favorables a su posición. ${ }^{31}$ Es cierto, la redacción de los documentos del papa Pío IX era intencionalmente ambigua, nuestro autor simplemente la leyó a su favor y descartó todo aquello que el mismo monseñor Gaume estimaba como signo de aprecio por parte del sumo pontífice. ${ }^{32}$ En fin, en una bella paradoja, Rivera llegó a comparar la suerte del ultramontano Ver rongeur en Roma, con el aprecio en la misma curia de la Defensa de los cuatro artículos, documento fundamental del galicanismo, de Jacques-Bénigne Bossuet. ${ }^{33}$

Hechas estas acotaciones, conviene aclarar que Rivera tampoco se situó en una postura radical: lo esencial de su argumentación, su "proposición”, como él mismo decía, era que "es muy útil enseñar a la juventud" los clásicos paganos desde una edad temprana, pero "con discernimiento"

particular al obispo Dupanloup, e incluso a los “antigaumistas” españoles, como Menéndez Pelayo y Emilio Castelar.

30 Rivera, Ensayo sobre la enseñanza de los idiomas latino y griego, pp. 50-51 en particular.

31 Rivera, Ensayo sobre la enseñanza, pp. 89-92 y 275-289.

32 Empero, es verdad que no llegó a ver colmadas sus expectativas en Roma: "La citadelle du gallicanisme, lui disaient ses amis, est à Saint-Sulpice, celle du paganisme au Gesù", señalaba Wenger, "La querelle des ultramontains", p. 838.

${ }^{33}$ Rivera, Ensayo sobre la enseñanza, pp. 55 y 277. 
y junto con los "clásicos cristianos". ${ }^{34}$ Mientras que monseñor Gaume, hablaba al menos de presentarlos altamente expurgados, sólo en una edad tardía, definitivamente excluirlos. Por ello al padre Rivera le parecía que el tenor de la encíclica de 1853 le era favorable: "el Papa quiere que se enseñen juntos” clásicos paganos y cristianos. ${ }^{35}$ Postura moderada, que le permitía incluso compartir algunos lamentos de su rival a propósito de los abusos en el uso de los autores antiguos, ${ }^{36}$ pero que no dejaba de insistir en que no eran necesariamente perjudiciales.

Rivera pues, debió proceder a fundamentar su tesis, la utilidad del estudio de los clásicos paganos, siempre "con discernimiento" y junto a los cristianos, ${ }^{37}$ al mismo tiempo que a discutir el triunfalismo de los "gaumistas" respecto de la aprobación pontificia, pero además debió discutir sobre al menos otras tres líneas. En principio, no dejó de utilizar a los propios Gaume y Ventura contra ellos mismos, por las contradicciones, entre uno y otro, dentro de sus obras, o entre las obras de un mismo autor. ${ }^{38}$ Mas en segundo lugar, el verdadero desafío de la obra de Gaume, La Révolution, era su tesis histórica: los clásicos paganos no se habrían usado en la enseñanza cristiana de los primeros siglos (sus principales pruebas eran testimonios de San Gerónimo y San

\footnotetext{
${ }^{34}$ Rivera, Ensayo sobre la enseñanza, pp. 58-61.

35 Rivera, Ensayo sobre la enseñanza, p. 91.

36 Por ejemplo, Rivera, Ensayo sobre la enseñanza, pp. 101-106.

37 A esto dedicó las adiciones 6 a 9 y 14 a 23. Rivera, Ensayo sobre la enseñanza, pp. 20-42 y 61-112.

38 A monseñor Gaume le reprocha, por ejemplo, su admiración por las obras de arte de la Roma renacentista unos años antes de que escribiera Le ver rongeur; Rivera, Ensayo sobre la enseñanza, p. 66.
} 
Agustín $)^{39}$ e incluso de la Edad Media, en particular bajo Carlomagno, cuando directamente fueron prohibidos por iniciativa de Alcuino. ${ }^{40}$ Habría sido durante el Renacimiento cuando se convirtieron en elemento fundamental de la educación de colegios jesuitas, que eran de las principales víctimas de los "gaumistas". Rivera por ello debió dedicar la mayor parte de su Ensayo a un recorrido histórico justo arguyendo lo contrario, en que terminaba haciendo una verdadera historia de la educación cristiana, del idioma latino e incluso de la escritura. ${ }^{41}$

En tercer lugar, nuestro autor lució en el Ensayo toda la erudición de que era capaz, pero pareciera una erudición en particular selectiva: en todo el texto se citaron al menos 111 autores distintos. Como si se tratara además de salvar de alguna forma el honor de la Compañía de Jesús, 17 de ellos eran jesuitas, ${ }^{42} 16$ eran clásicos paganos y cristianos; $;{ }^{43}$

39 De ahí los extensos desarrollos de Rivera, Ensayo sobre la enseñanza, pp. 173-182 y 280-231 respecto de estos padres de la Iglesia latina.

${ }_{40}$ Siendo un dato cierto, Rivera se ocupó por tanto de descalificar como novedad lo hecho por Alcuino, en Rivera, Ensayo sobre la enseñanza, pp. 317-335.

${ }^{41}$ A esto dedicó las adiciones de la 24 a la 37, 39 y 40 y 43 a la 55. Rivera, Ensayo sobre la enseñanza, pp. 112-231, 241-273 y 293-376.

42 Alápide, Alonso Rodríguez, Juan de Mariana, René Rapin, Juan Álvarez de la Paz, Nicolas Caussin, Francisco Suárez, Gregorio Garcés, Juan Andrés y Morell, Francisco Xavier Idiáquez, Jean-Nicolas Grou, Marco Emerich, Francisco Xavier Alegre, Pierre Olivet, Arsène Cahour y Basilio de Arrillaga.

${ }^{43}$ Apuleyo, Catón el filósofo, Cicerón, Diódoro de Sicilia, Esopo, Horacio, Plutarco, Quintiliano, San Agustín, San Gerónimo, San Gregorio Nacianceno, San Inocencio I, Séneca, Teodoreto de Cyr, Terencio, Virgilio. No se incluyen más que citas propiamente dichas, y no otras referencias y alusiones. 
por naciones, los grupos más notables son los 31 franceses y 31 españoles. De manera semejante a lo que había hecho en sus Inscripciones, en la novena adición presentó una serie de "Encomios de los clásicos cristianos y de los clásicos paganos acondicionados" ${ }^{44}$ en que reunió a su favor una galería de 40 citas de 31 autores, desde la Biblia hasta el siglo XIX. Por cierto, de nuevo se notan las preferencias de Rivera: 11 eran franceses y 8 de éstos del siglo xvir. ${ }^{45}$

Para el extenso recorrido que forma la mayor parte del Ensayo, nuestro autor se sirvió de una amplia serie de historiadores y eruditos de los siglos XVI al XIX, pero sobre todo de diez: Alápide, Melchor Cano, Louis Thomassin, Juan Alzog, César Cantú (de quien retomó una mirada moderada de la Edad Media), por supuesto fray Benito Gerónimo Feijoo, Juan Andrés y Morell, Francisco Javier Idiáquez, Arsène Cahour, e incluso François Guizot. Aprovechó además a los canonistas y sus historias del derecho eclesiástico, como las de Manuel González Téllez, Benedicto XIV (sobre todo para el tema de los cánones medievales), Carlo Sebastiano Berardi y el Barón Henrion.

Todo este empeño tenía sentido por varios motivos. Desde el inicio de su correspondencia con el obispo de León, Rivera se había sentido personalmente afectado por las ideas de monseñor Gaume y del padre Ventura. Mas no era sólo por él: una de las primeras adiciones, la quinta, recuerda a "los Portugal, Munguía, Sollano, Ormacheas, Nájeras,

44 Rivera, Ensayo sobre la enseñanza, pp. 30-42.

45 Alápide, Jean-Louis Balzac, Dom Mabillon, Jean de la Bruyère, Jean de Santeuil, René Rapin, Fénelon, Fleury, Louis Thomassin, el abate Mably, Arsène Cahour y Dübner (alemán, pero que hizo buena parte de su obra en Francia). 
Arrillagas, Camachos, Espinosas, Pesados, Carpios, Sánchez de Tagle, Marianos Esparzas, Alamanes, Coutos, De la Rosa y mil otros, sí, mil otros mexicanos ilustres". ${ }^{46} \mathrm{La}$ educación clásica era un elemento indispensable de la cultura nacional para Rivera, mas no exclusivamente eclesiástica. Lo hemos visto adornar con citas de clásicos latinos las paredes del Liceo de Lagos, el Ensayo incluyó además una bella evocación del modelo de lo que Rivera estimaba como el ideal de la educación de la niñez y la juventud, estrechamente relacionada, en efecto, con el estudio del latín. ${ }^{47}$

Pero, sobre todo, se entiende bien en ciertos puntos del Ensayo, que Rivera despliega todo ese esfuerzo para seguir defendiendo la tesis que sostuvo en su Concordancia sobre la relación entre la naturaleza humana y la gracia divina; la primera, repetimos, capaz del conocimiento de ciertas verdades, independientemente de la revelación religiosa. De ahí su exasperación con monseñor Gaume, que trataba de clasificar todo en función de esta última (de la religión): con el clérigo ultramontano, había no sólo "clásicos cristianos" o "clásicos paganos", sino incluso un latín cristiano y uno pagano; el primero debía, evidentemente, imponerse sobre el segundo. Rivera ridiculizó ampliamente esta idea ${ }^{48}$ pero además no pudo sino apoyarse de manera particular en el padre Arsène Cahour: La Religion du Christ ne devait pas anéantir les langues qui ont servi à la prédication de l'Évangile. Elle venait redresser, perfectionner l'bumanité, et non pas la détruire. ${ }^{49}$ Frente a la definición

${ }^{46}$ Rivera, Ensayo sobre la enseñanza, p. 19.

${ }^{47}$ Rivera, Ensayo sobre la enseñanza, pp. 134-139.

${ }^{48}$ En particular Rivera, Ensayo sobre la enseñanza, pp. 107-108.

49 Rivera, Ensayo sobre la enseñanza, pp. 98-100, la cita en p. 99. 
en términos exclusivamente religiosos, Rivera se reafirmaba en una antropología moderada: "Todo idioma considerado en sí mismo, no es pagano, sino natural y moralmente bueno", llegó a afirmar. ${ }^{50}$

¿Qué eran entonces las ideas de esos clérigos ultramontanos? Rivera citaba con elocuencia a Descartes a manera de epígrafe al inicio de sus adiciones: Il n'est pas plus aisé à un bomme de se défaire de ses préjugés que de brûler sa maison. ${ }^{51}$ En varios pasajes del ensayo insistió sobre el punto, advirtiendo con ironía a los "gaumistas" que evitaran efectivamente quemar sus casas: monseñor Gaume actuaba dominado por prejuicios, que rayaban en la superstición. "Huyamos del purismo supersticioso de algunos excesivamente afectos a los clásicos cristianos", ${ }^{52}$ advertía nuestro autor. En efecto, quienes únicamente veían perjuicios en la enseñanza de los autores antiguos paganos, no eran sino "sabios preocupados", que por lo mismo podían incluso ser ridiculizados por sus "preocupaciones". Rivera lo hizo con cierta extensión en el folleto de 1881 Los dos estudiosos a lo rancio ${ }^{53}$ cuya primera versión incluyó en la adición 38 del Ensayo.

El padre Rivera, pues, marcó con mayor fuerza su distancia de los polemistas católicos ultramontanos franceses. Aunque al igual que Auguste Nicolas, monseñor Gaume le mereció ciertos reconocimientos, no dudó en ironizar sobre su obra: al final, el principal argumento del clérigo francés era un sueño medieval, el de Alcuino, el que había estado

50 Rivera, Ensayo sobre la enseñanza, p. 108.

51 Rivera, Ensayo sobre la enseñanza, p. 15.

52 Rivera, Ensayo sobre la enseñanza, p. 106.

53 Rivera, Los dos estudiosos a lo rancio, pp. 128-147. 
en el origen de la supresión de los estudios de los clásicos antiguos. ${ }^{54}$ Es cierto, para cuando Rivera publicaba la última entrega del Ensayo, ya habían muerto tanto el padre Ventura como monseñor Gaume, e incluso el "gaumista" nacional, el obispo Díez de Sollano y Dávalos, y los alcances de los "gaumistas" se revelaban limitados. El padre Rivera pudo dirigir su pluma a otros lances en la década de 1880, algunos anunciados ya en el Ensayo y en Los dos estudiosos. En este último, por ejemplo, Rivera se refiere ya a "una literatura endemoniada" o a la "bella literatura fea", ${ }^{55}$ que estaba íntimamente asociada con Francia.

\section{MAL GUSTO ROMÁNTICO Y RETRATO DE CARACTERES \\ CORTESANO: LITERATURA Y MORAL}

En 1883, Agustín Rivera y Sanromán, quien el año anterior había renunciado a la capellanía de las religiosas capuchinas, "vivía en Lagos y escribía un pequeño libro intitulado Ensayo sobre la enseñanza de los clásicos paganos a los jóvenes y a los niños". ${ }^{56}$ En ese mismo año dio a la prensa su Descripción de un cuadro de veinte edificios, largo ensayo motivado por una pintura que mandó hacer, efectivamente con 20 edificios célebres en 4 series de 5 . Ahí incluyó dos de la ciudad de París: la Catedral de Notre-Dame y el palacio de las Tullerías. Fue particularmente breve en su descripción, pero en cambio es en particular provechosa por una extensa

54 Rivera, Ensayo sobre la enseñanza, pp. 324-335.

55 Rivera, Los dos estudiosos a lo rancio, p. 23, y en general pp. 21-31.

56 Rivera, Ensayo sobre la enseñanza de los idiomas latino y griego, p. 231. 
nota al pie dedicada a la crítica de la literatura francesa de ese momento, sobre todo de un autor: Victor Hugo. ${ }^{57}$

Ante Notre-Dame de París, Rivera no pudo dejar de evocar la novela de ese título, "con la que abrió su marcha la pobre literatura romántica”, afirmó de inmediato. Pobre, no por falta de talento, sino porque nuestro autor reprochaba en el romanticismo ni más ni menos que el "mal gusto", esto porque "se deleitaran y celebraran como cosas bellísimas figuras, conceptos y argumentos que son claramente unas fealdades", afirmó sin mayores matices. ${ }^{58}$ Curiosamente de inmediato comparó al novelista francés y otros románticos (Alexandre Dumas, suponemos que el padre, y Eugène Sue) con los autores del Siglo de Oro español: unos y otros salían perdiendo justo por compartir el mismo problema estético. En cambio, sólo vinieron a la pluma del autor modelos clásicos (Homero), medievales (Dante Alighieri) y del siglo xvir español (Francisco de Quevedo), a más de una larga lista de autores novohispanos y mexicanos, barrocos y neoclásicos en su mayoría, para contrastarlos con los autores que criticaba; es decir, ningún literato francés.

Rivera no llegó a disertar ampliamente en ese momento sobre el gusto y sus características, aunque dejó al menos asentado un principio teórico: el buen gusto, afirmaba, no era sólo "sentimiento" sino también "una vista o percepción intelectual de la belleza". ${ }^{59}$ Cabe reconocerle que advirtió

57 Rivera, Descripción de un cuadro, pp. 67-68.

58 Ya en Los dos estudiosos a lo rancio, p. 23, RIVERA retomaba las críticas de los clasicistas contra los románticos por medio de la Enciclopedia de Mellado, señalando además "un exagerado sentimentalismo, o una completa desnudez, o cosas contrarias a la verosimilitud”.

59 Ya el año anterior había publicado una explicación, breve también, 
que no era algo natural sino social, procedente de la formación de los individuos; el mal gusto, pues, podía producirse "por educación u otro hábito o por enfermedad". Pero, sobre todo, en un párrafo en que el autor no se ahorró adjetivos, quedaba claro que en realidad lo que demandaba a la literatura era lo mismo que en las citas docentes que reunió en 1869: moralidad. Lo que rechazaba de los románticos era su gusto por lo oscuro. Lo decía con claridad: era una poesía que "desdeña a Dios, el cielo, la verdad, la virtud, el honor, el valor, la gloria, el amor, la esperanza, la felicidad y todo lo que es grande, noble, generoso, dulce [...]" y un largo etcétera. En cuanto a la prosa, ya el año anterior había afirmado: "El mundo es bastante malo, pero esos novelistas lo pintan más malo de lo que es" ${ }^{60}$ No lo decía de forma explícita, pero quedaba claro que de ahí no podían obtenerse enseñanzas y antes bien concluía la nota con una enfática advertencia a la juventud contra el romanticismo, que sólo podía llevar "a la penitenciaría y al suicidio". ${ }^{61}$

Había un detalle técnico que Rivera mencionó en esas líneas, aunque sin darle demasiado énfasis. Victor Hugo y los románticos descuidaban "presentar los caracteres y los hechos con naturalidad y verosimilitud". ${ }^{62}$ En cambio, un

aunque algo oscura, sobre la definición del buen gusto: "El buen gusto, en cuanto a la sustancia, es tan común como el sentido común, o para mejor decir, es el sentido común de lo bello [...]. El buen gusto, en cuanto a su finura, es propio de pocos; pero pocos de cada una de las naciones civilizadas del mundo [...]". Rivera, Los dos estudiosos a lo rancio, pp. 27-28. ${ }^{60}$ Rivera, Los dos estudiosos a lo rancio, p. 30.

${ }^{61}$ Rivera, Descripción de un cuadro, pp. 67-68. En contraste, ya en RiveRA, Los dos estudiosos a lo rancio, p. 24, se hacía alusión al "primer deber del novelista y dramaturgo [que] es el pintar la virtud y hacerla amable". ${ }^{62}$ Rivera, Descripción de un cuadro, p. 67. 
adecuado "retrato de caracteres” lo encontró Rivera, así como otras virtudes literarias, más bien en la oratoria sagrada, en particular, aunque no exclusivamente, en la de los siglos XVII y xvin franceses. Ya es elocuente al respecto uno de los textos breves que nuestro autor recopiló en su folleto El Cempazúchil (1891), titulado "Paralelo entre Cicerón y Massillon”.

En las dos breves páginas en que el texto corresponde a su título - pues en las siete siguientes nuestro autor deriva hacia temas históricos - , en realidad quien hizo el paralelo entre el autor clásico pagano y el predicador francés de fines del Xvir fue el obispo Clemente de Jesús Munguía en sus Estudios Oratorios. ${ }^{63}$ El tema del paralelismo eran los recursos del orador para emocionar a su público: Cicerón lo había logrado a través de "la interrogación bien manejada", Jean-Baptiste Massillon había hecho otro tanto, e incluso, en opinión del prelado, había superado con creces al autor romano. En las extensas citas de quien fuera su maestro, se destaca el doble carácter de la oratoria sagrada: juzgada al mismo tiempo por sus virtudes estéticas, pero también por sus fines religiosos. Si Massillon superaba a Cicerón, era porque "conmueve e instruye; ilustra y confunde, y lleva la antorcha espantosa de la verdad hasta el fondo de un alma desengañada", que no podía sino derramar lágrimas. ${ }^{64}$ Tal pues la virtud que Rivera no encontraba en la literatura romántica: le reconocía talento, pero no la encontraba útil para la conversión.

Ahora bien, si Rivera no discutió esa virtud como propia, Massillon destacó por su parte a Charles Frey de Neuville,

${ }_{63}$ Rivera, El Cempazúchil, p. 16.

${ }^{64}$ Rivera, El Cempazúchil, p. 17. 
jesuita y predicador de tiempos de Luis XV, por su "profundidad", esto es, justo por lo que decíamos: su capacidad para la "pintura de caracteres". Tal fue el motivo por el que en 1893 publicó el folleto con el rimbombante título de $\mathrm{La}$ pobre humanidad a través de la púrpura, el cetro, el libro, el laurel y el crucifijo o sean pensamientos muy filosóficos del sermón de Carlos Neuville, de la Compañía de Jesús y orador de Luis XV sobre el Genio.

Se trata, desde luego, de una transcripción de amplios pasajes del sermón, con una introducción y no menos amplias notas al pie del padre Rivera. A pesar del extenso elogio inicial, en realidad hay que esperar al sermón mismo para entender cabalmente el motivo de la fascinación de nuestro autor por la pintura de caracteres del jesuita. La introducción resalta en cambio por el diálogo que entabla Rivera con un crítico español de tiempos de la Restauración de Fernando VII: José Mamerto Gómez Hermosilla, autor neoclásico en lo estético y auténtico reaccionario en lo político. ${ }^{65}$ Sobre el sermón, Rivera nos explica su relación ya larga con el texto: "Desde mi juventud leí estos Sermones y la impresión que me causó el que trata de El Genio no se ha borrado de mi memoria", ${ }^{66}$ afirmaba sin dar otras explicaciones. Empero ya el cierre de la introducción dejaba ver que el elogio tenía, de nuevo, fundamentos morales, en buena medida relacionados con su propia postura teológica según la hemos visto formulada ya en su Concordancia: el "genio" de Neuville era la naturaleza, "es el modo de ser peculiar" o "modo de ser natural e individual", obviamente

${ }_{65}$ Rivera, La pobre humanidad, pp. 1-4.

${ }^{66}$ Rivera, La pobre humanidad, p. 3. 
defectuoso y que "con el auxilio de la razón y de la gracia" era necesario "reprimir y rectificar" ${ }^{67}$ Esto es, aunque nuestro autor no lo dirá con todas sus letras, se entiende que la pintura de caracteres era fundamental, era necesaria en la oratoria sagrada pero incluso en cualquier otro género literario, porque hacía realmente provechosa a la literatura, no en términos de una estética libre e independiente, secularizada digamos, sino para un fin superior, de orden religioso.

Es cierto, además, que la pintura de caracteres tenía también un aspecto político. Ya lo habíamos mencionado, es en parte por ello que el paralelo entre Cicerón y Massillon terminó en recuento de historia política mexicana. En sus notas al pie del Sermón de Neuville, Rivera desarrolla con amplitud y de nuevo aterrizándolo al caso nacional la pregunta del predicador del siglo xvir: en el conocimiento del genio “ ¿No estriba, digo, en este principio el arte y la política del mundo?”. ${ }^{68}$ En esas notas cobra sentido el título del folleto: aunque no incluye un relato íntegro de la historia de la humanidad, se diría que ésta puede leerse según el genio de sus gobernantes, a través del cetro; es decir, el genio del gobernante autoritario; el libro, el genio del que "gobierna según los dictámenes de su razón”, e incluso el crucifijo. En este último caso, se trata del gobernante religioso, pero que no logra ver la gracia sino en lo que es más adecuado a su genio, en lugar, por el contrario, de buscar aquello que lo reprima y perfeccione. Tal es, ya lo hemos visto con el caso de monseñor Gaume y del padre Ventura, una de las ideas fuertes de Rivera: "Una añeja preocupación, robustecida con la educación y con las ideas de la época

67 Rivera, La pobre humanidad, p. 4.
68 Rivera, La pobre humanidad, p. 8. 
y autorizada por muchísimas personas, es como una venda en los ojos, sumamente difícil de quitar". ${ }^{9}$

Esta última tesis tiene consecuencias no sólo para la política, o para la disciplina eclesiástica como vimos atrás, sino también para la práctica de la religión. Mas antes de llegar a ello, destaquemos que esas notas al pie forman una breve "teoría del genio", por así decir, en que Rivera, manifestando leves desacuerdos con Neuville, aprovecha su serie de 13 distintos caracteres para identificar ya no sólo sus consecuencias políticas, sino las reglas mismas de su funcionamiento. La más básica resulta ser la compatibilidad de genios semejantes: "la regla general", decía, era que "la conformidad de genios une los corazones por medio del amor o de la amistad". ${ }^{70}$ Las notas se extienden en varias consecuencias, casos particulares en que justo la proximidad en otros aspectos no llega a subsanar las diferencias en el "genio".

Sin hacer un tratado sistemático, el autor al menos no nos deja con la duda de los elementos que contribuyen a formar o modificar el genio. En conformidad con la antropología que ya le hemos visto expresar, el fundamento del genio no puede ser sino la naturaleza: "en su sustancia viene solamente de la naturaleza”. Naturaleza que aquí casi puede confundirse con nación, pues de ella "principalmente" provenía para Rivera el "carácter nacional”. Esto es, las naciones eran algo natural para nuestro autor y más todavía, eran el elemento sustancial para construir los caracteres individuales. Empero, Rivera utilizó el concepto de "hábito" para referirse a aquello que podía modificar al genio, clasificándolo en

${ }^{69}$ Rivera, La pobre humanidad, p. 10.

70 Rivera, La pobre humanidad, p. 15. 
cuatro categorías: la religión, la educación primera, el Estado y la práctica de la virtud, que tenía por mayor consecuencia la santidad. Casi es obvio que esta última es la más importante, pues se detiene en tres retratos contrastados de la naturaleza y la santidad, entre los santos primero, luego los apóstoles, para terminar en Jesucristo mismo, verdadero límite de la teoría que apenas si alcanza a explicar; pero insiste sin embargo: "en cuanto hombre, tenía su genio: genio perfectísimo, pero era su genio con el que nació y murió". ${ }^{71}$

Ahora bien, Neuville resulta de gran importancia para Rivera porque él mismo se extendió en el tema de la relación entre genio y religión, acuñando la expresión de "piedad de genio", aquella "llena de defectos [...] una piedad extravagante e indiscreta; una piedad contumaz y amiga de su dictamen; una piedad soberbia y crítica". ${ }^{72}$ Conviene detenernos brevemente sobre el sermón recuperado y explotado por Rivera: en realidad se trata del sermón Sur la nécessité de réprimer son bumeur, escrito por el padre Frey de Neuville para el segundo domingo de Adviento. ${ }^{73}$ Esto es, lo que se tradujo al español como "carácter" o "genio", era en francés bumeur. El sermón consta de dos partes, la primera dedicada a los distintos bumeurs, la segunda claramente es más combativa contra "des dévots dominés par l'humeur", "accoutumés à prendre les faillies de l'humeur pour les mouvements de la grâce", eran capaces incluso de condenar a todos los que los condenaban. El jesuita no lo dice explícitamente; en

71 Rivera, La pobre humanidad, pp. 19-20.

72 Rivera, La pobre humanidad, p. 18.

73 Frey de Neuville, Sermons, pp. 195-224. 
el contexto de la Francia del siglo xviII, es difícil no leer en ellos a los jansenistas. ${ }^{74}$

Rivera, pues, ha dado con una segunda controversia francesa, más extensa que la anterior, pero también más distante. En realidad, no necesitaba saber del contexto del sermón; antes bien, ni una sola vez se refirió al jansenismo y no hemos encontrado referencia al respecto en sus obras. Pero la querella del jesuita del siglo xvirI le sirve a él para su crítica de la cultura religiosa del mundo hispánico en al menos dos puntos concretos. En primer lugar, en sus notas al pie, se extiende por su parte en ejemplos nacionales y locales para esa "piedad genial" o "piedad indiscreta", que casi siempre declinan en ejemplos femeninos. ${ }^{75}$ Además, en segundo lugar, retoma para México la denuncia de la multiplicación de los "sistemas de devoción” de Neuville. Pero nuestro autor apunta no sólo a las devociones tradicionales del mundo hispánico, en efecto numerosas, sino también y paradójicamente a las nuevas del siglo xix, propias de la piedad ultramontana: "el Mes [de] María, Mes del Sagrado Corazón de Jesús, Mes del Rosario, Mes de las Ánimas, Mes del Señor San José, la Hora Santa, el Apostolado de la Oración, la Guardia de Honor al Sagrado Corazón de Jesús [...]" y un largo etcétera. ${ }^{76}$ En todo ello, Rivera insistía en reprochar la falta de culto interior, frente a los excesos del fasto que "halagaban los sentidos" y servían más bien para la vanidad individual, puntos que desde luego no aparecen

\footnotetext{
74 Frey de Neuville, Sermons, pp. 208 y 211 para las citas. Sobre la querella jansenista en el siglo XviII: MaIre, De la cause de Dieu; CotTret, Jansénismes et Lumières, y VAN KLEY, Les origines religieuses.

75 Rivera, La pobre humanidad, pp. 2, 23 y 26 especialmente.

76 Rivera, La pobre humanidad, pp. 25 y 26.
} 
en el sermón de Neuville, del que en cambio debe pasar por alto el tema de las penitencias, ${ }^{77}$ que probablemente hacían alguna alusión al movimiento convulsionario. ${ }^{78}$

La oratoria francesa de los siglos XviI y xviII servía pues a Rivera para teorizar de nuevo sobre una antropología católica y - de manera muy directa en la nota final del folleto que comentamos $-{ }^{79}$ para criticar la cultura religiosa hispánica y ultramontana desde una postura no menos católica. Es por ello que veía la virtud de la originalidad en un texto que, finalmente, era un producto muy clásico de una cultura cortesana particularmente refinada, que se había ido especializando en el tema del conocimiento de los individuos y su caracterización, ${ }^{80}$ y de un combate propio de la Compañía de Jesús, tan lejos de las preocupaciones de nuestro autor, que hasta donde sabemos ni siquiera lo percibió.

Tal era pues, para nuestro autor, la literatura en una de sus más notables expresiones, y no la "bella literatura fea" que daba rienda suelta al sentimentalismo y a la imaginación, sino por el contrario, una literatura que servía para al menos denunciar las "preocupaciones" y los "genios" mal encaminados. Acaso por ello mismo, justo en esos años, comenzó a recuperar a otro autor francés, con el que compartía el deseo de régner sur les préjugés.

77 Frey de Neuville, Sermons, 1777, pp. 217-218 y Rivera, La pobre bumanidad, p. 27.

78 Sobre ese movimiento remitimos en particular a MAIre, De la cause de Dieu, pp. 238-324.

79 Rivera, La pobre humanidad, pp. 29-31.

80 Recordemos al respecto las tesis clásicas de ELÍAs, La sociedad cortesana, pp. 138-141, sobre "el arte de observar a los hombres". 
COMBATES CONTRA PREJUICIOS Y MIRADAS DE LA HISTORIA:

PROVIDENCIA Y PROGRESO

En 1890, Agustín Rivera y Sanromán, autor ya para entonces de al menos unas 40 obras, enfermó de la vista mas no por ello dejó de publicar. ${ }^{81}$ Por el contrario, en esa quinta década de su carrera literaria (1887-1897) produjo un total de 44 textos, 10 de los cuales fueron fechados en 1891. Fue así como surgió una serie de folletos que se cuentan entre los más difundidos de nuestro autor, titulada "Entretenimientos de un enfermo". Uno de esos folletos, fechado en Lagos, el 6 de enero de 1891, justo en el periodo más difícil de su enfermedad, lleva el título de Tres artículos de Agustín Rivera sobre el elogio que en su arenga del 27 de octubre próximo pasado bizo de los Principios proclamados por la Revolución Francesa de 1789. ${ }^{82}$ Tres años más tarde, publicaría además un Paralelo entre el Contrato social de Juan Jacobo Rousseau y el Sermón del Illmo. Sr. D. Antonio Joaquin Pérez, obispo de Puebla, predicado en el púlpito de su Catedral en pro del Plan de Iguala, el día 5 de agosto de 1821, delante de Iturbide. ${ }^{83}$ Uno y otro constituyen los textos en que Rivera trató de manera más directa con el pensamiento y acontecimientos más radicales de la historia francesa.

Vamos a comenzar por su relación con el célebre "ciudadano de Ginebra”. Conviene destacarlo, no es que antes de estas fechas nuestro autor desconociera a Rousseau, pero

81 Rivera, Bodas de oro, p. 21.

82 Rivera, Tres artículos.

83 Rivera, Paralelo entre el Contrato social. 
el uso que hacía de su referencia era más bien negativo. Volvamos por un momento a la Concordancia de 1876, al momento en que Rivera criticaba a Auguste Nicolas. Entonces advertía de su peligrosidad, tanto mayor porque se trataba de un apologista católico, que por ello sería de entrada valorado positivamente, mas "la referida doctrina hará más mal que una doctrina de Rousseau”, sentenció. ${ }^{84}$ No estimó necesaria explicación alguna, se sobreentendía que JeanJacques Rousseau no podía sino ser un autor, al menos, negativo en el plano de la filosofía moral, hasta los jóvenes estudiantes a los que estaba dirigido el folleto debían entenderlo con facilidad.

Esta referencia negativa se matiza más adelante. En 1880, al mismo tiempo que combatía el pensamiento de monseñor Gaume, Rivera comenzó a publicar una serie de folletos titulada Miscelánea selecta, o sea Colección de sentencias, pensamientos, trozos y noticias escogidos de muchos autores, que terminó teniendo, hasta donde sabemos, sólo dos números, el de ese año y una "Entrega 2a", según su portada, impresa en $1889 .{ }^{85}$ En ésta aparecían sobre todo relatos de la historia nacional, pero en la última página aparecía una sola cita, muy breve, justamente de Rousseau, y además en su idioma original: Voulez-vous régner sur les préjugés? Commencez à regner par eux..$^{86}$ De hecho, Rivera ya la había citado en una ocasión en el intervalo entre las dos partes de la Miscelánea, en su diálogo Los dos estudiosos a lo rancio de 1882. ${ }^{87}$ No hemos podido identificar la procedencia exacta

\footnotetext{
${ }^{84}$ Rivera, Concordancia de la razón y la fe, p. 16.

85 Rivera, Miscelánea selecta.

86 Rivera, Miscelánea selecta, p. 193.

87 Rivera, Los dos estudiosos a lo rancio, p. 119.
} 
de la cita, aunque sabemos que ya circulaba en obras francesas de la década de 1780, así como en México desde la independencia. ${ }^{88}$ En la Miscelánea Rivera le asignó como título "Medio para vencer las añejas preocupaciones", mientras que en Los dos estudiosos la tuvo como "uno de los principios de los filósofos civilizadores". ${ }^{89}$ Bien podemos suponer que justo por ello, porque como hemos visto, una de las preocupaciones de Rivera era encontrar los medios necesarios para vencer los prejuicios o supersticiones, a todos los niveles, desde los "populares" (como sus paisanos laguenses) hasta los de los "pensadores" más refinados y católi$\cos$ (como monseñor Gaume), Rousseau pudo entrar en su catálogo de citas.

No es que Rivera se "reconciliara” plenamente con Rousseau, la condenación directa desaparece, pero no dejó de usarlo con un matiz levemente negativo, en particular en el Paralelo, de 1894. Al igual que su equivalente entre Cicerón y Massillon, en realidad se trata de un texto breve, aunque esta vez es el propio Rivera quien pone en relación fragmentos de El Contrato social y del sermón del obispo Pérez Martínez, literalmente los pone frente a frente en dos

${ }^{88}$ Aparece en Le triomphe du Nouveau Monde (1785), p. 279 y en la advertencia inicial de De l'État naturel des peuples (1786), p. ix. En México la citó Francisco Severo Maldonado en su Nuevo pacto social propuesto a la nación española (1821).

${ }^{89}$ Conviene recordar que, en Rivera, Los dos estudiosos a lo rancio, pp. 103-104, nuestro autor estaba tratando de situar con precisión al personaje de Quetzalcóatl; la cita de Rousseau sirve para enmarcarlo en la categoría de legislador, pero también para argumentar en contra de la tradición que hacía de él un apóstol. Rivera era en particular refinado con las categorías, como puede verse. 
columnas en dos fragmentos de unas pocas líneas. ${ }^{90}$ Como de costumbre en sus folletos, las notas y las conclusiones del propio autor son casi tan extensas como el texto central y abordan otros temas, en este caso, de historia de la independencia. ${ }^{91}$ Según se entiende por los corolarios, nuestro autor prácticamente reprochaba al obispo Pérez utilizar, sin confesarlo, argumentos de Rousseau para justificar la independencia en 1821 a través del movimiento encabezado por Agustín de Iturbide, a pesar de haber trabajado antes, y duramente, en contra de ella. ${ }^{92}$

Así pues, ¿en que se parecían el texto del philosophe y el del prelado novohispano? En realidad, en el uso por ambos de la metáfora de la maduración en el seno de una familia para justificar la emancipación de un pueblo, pero se entiende que nuestro autor hacía al obispo un lector de Rousseau que había adoptado no sólo la ilustración sino también el fondo del argumento, el principio de la conservación según el interés individual, que además es justo el tema de la adición posterior que hizo al folleto. ${ }^{93}$ En segundo lugar estaba la alusión a la intervención de la Providencia en los asuntos políticos. Desde luego, Rousseau, secularizando la ciencia política, simplemente la descartaba como argumento remitiéndola al espacio propio de lo religioso: el púlpito.

\footnotetext{
90 Rivera, Paralelo entre el Contrato social, pp. 1-4.

${ }^{91}$ Rivera, Paralelo entre el Contrato social, pp. 5-10.

92 "De algo le sirvió el Contrato Social al Sr. Obispo Pérez", comenzaba el corolario $1^{\circ}$, mientras el segundo comienza: "Iturbide y los demás realistas en 1821, después de haber derramado y hecho derramar torrentes de sangre durante once años, vinieron a convenir en lo mismo que había proclamado Hidalgo". Rivera, Paralelo entre el Contrato social, p. 5.

93 Rivera, Paralelo entre el Contrato social, pp. 11-12.
} 
Y claro, en su sermón el obispo Pérez Martínez hacía alusión a la Providencia, declarándose un mero contemplador de sus "caminos ocultos", pero dejando implícito - o al menos así lo leía Rivera - el mensaje de que la campaña de Iturbide era efectivamente providencial. ${ }^{94}$ Paradójicamente Rivera no pudo sino agregar que "ni en el púlpito" era aceptable la tesis de la intervención providencial directa, "como se ve respecto del púlpito de Puebla”. ${ }^{95}$ Más todavía, en las notas al pie nuestro autor, manteniendo el tono recriminatorio hacia el obispo poblano, se preguntaba: “ ¿Con que la Providencia de Dios era la que disponía la Independencia de México de España? ¿Y todas las excomuniones anteriores? Ese día valieron cero". ${ }^{96}$

Crítico pues del obispo realista convertido en trigarante, Rivera empero no se manifiesta necesariamente en contra de los pasajes citados de Rousseau, antes bien se diría que acepta de alguna forma la mirada pesimista sobre la humanidad respecto de la importancia de interés individual, y sobre todo, reconoce la necesidad, ya que no de separar sí al menos de poner matices en la relación entre religión y política, de evitar los abusos de los que la guerra de independencia había dado varios ejemplos. ${ }^{97}$ Desde luego, hasta donde sabemos no llegará a aceptar la crítica de la "religión del sacerdote" de la obra de Rousseau. En cambio, su prioridad es proteger a la Providencia y también, siempre conforme con su antropología católica, la libertad natural del hombre. En efecto, sus notas marginales insisten en que si bien "todo

\footnotetext{
${ }^{94}$ Rivera, Paralelo entre el Contrato social, pp. 2-4.

${ }_{95}$ Rivera, Paralelo entre el Contrato social, p. 4.

${ }^{96}$ Rivera, Paralelo entre el Contrato social, p. 4.

97 Rivera, Paralelo entre el Contrato social, pp. 9-10.
} 
poder viene de Dios", mediatamente, mediante los hombres, es decir, el pueblo; y asimismo, la Providencia actuaba de manera "conciliable con la libertad del hombre". ${ }^{8}$ De nuevo terminaba advirtiendo contra un prejuicio religioso, como hemos visto en el apartado anterior: la humanidad, decía citando a San Agustín, "cree que la voluntad de Dios es la que sigue, cuando realmente es la suya propia”.

En la década de 1890, por tanto, Rivera, terminaba siendo crítico de la relación directa entre autoridad política y religión; no era de extrañar que en esos mismos años evocara incluso positivamente la memoria de la revolución francesa en el marco de las ceremonias cívicas laguenses. Tal fue el origen de su folleto Tres artículos (1891): habiendo recibido la visita de las autoridades y Junta Patriótica de Lagos, "les hablé del progreso social" y por tanto de los principios de la revolución francesa. ${ }^{99}$ Según su propio decir, volvió a sus referencias galicanas y citó al obispo Dupanloup: “Aceptamos e invocamos los principios y las libertades proclamados en 1789 ". 100

Si algo es interesante en la vida y obra de Rivera, es su capacidad para, residiendo en Lagos, generar reacciones en la opinión pública, sobre todo de Guadalajara, pero incluso también en la Ciudad de México. Hubo reacciones tanto positivas como negativas en la prensa, que lamentablemente no hemos podido identificar aún. Nuestro autor era bien consciente de todo ello. Para seguir con los paralelos con los movimientos religiosos europeos, jansenistas y galicanos, y

\footnotetext{
${ }^{98}$ Rivera, Paralelo entre el Contrato social, pp. 2 y 8.

99 Rivera, Tres artículos, p. 6.

100 Rivera, Tres artículos, p. 6.
} 
con el buen humor que le distinguía, Rivera afirmó: “con motivo de mi arenga [...] hubo una bulla tan grande como la Bulla Auctorem fidei" ${ }^{101}$ Sus Tres artículos, sobre todo los dos primeros, fueron su respuesta a esa controversia.

Con su habilidad característica, nuestro autor se escudó en la autoridad episcopal de monseñor Dupanloup y en largas citas del "sermón de la Vocación de la Francia" del padre Lacordaire y de la Historia de los Girondinos de Alphonse Lamartine. ${ }^{102}$ Además, como hizo en su discusión de monseñor Gaume, leyó a su favor el magisterio pontificio. ${ }^{103}$ Desde luego, partía del deslinde entre los "derechos y los hechos", los principios y los crímenes revolucionarios. ${ }^{104}$ Sobre todo, aprovechaba además la memoria de la Revolución como expiación de Lacordaire y los hechos relatados por Lamartine, para subrayar los vicios del Antiguo Régimen, todo ello vinculando la independencia mexicana con la Revolución francesa. Esto lo lleva a concluir el artículo $1^{\circ}$ sentenciando: “'Triste condición humana! Un pueblo no puede regenerarse sin una revolución social. No hay revolución social sin sangre". ${ }^{105}$

Todo ello nos lleva naturalmente al último folleto que nos interesa analizar: El progreso lento y el radical en la destrucción de la esclavitud en las naciones cristianas (1897). Nos interesa sólo el primero de sus bocetos, pues contiene algunos principios interesantes que clarifican en parte lo anterior: ante todo, la fe de Rivera en el progreso. "El progreso

\footnotetext{
101 Rivera, Tres artículos, p. 7.

102 Rivera, Tres artículos, pp. 2-3.

103 Rivera, Tres artículos, p. 5, tal fue el segundo breve artículo.

104 Rivera, Tres artículos, p. 1.

105 Rivera, Tres artículos, p. 4.
} 
en el orden físico y en el moral es una ley general, perpetua e invariable de la naturaleza". ${ }^{106}$ Pero como siempre, hay matices: Rivera distingue el progreso lento del radical, pero de ambos puede decir que son "conforme a las leyes de la naturaleza”, sólo que el último es, además, violento; producía incluso la guerra. ${ }^{107} \mathrm{La}$ "civilización en la edad moderna y en la edad contemporánea" se distinguía por ese tipo de progreso, ocupando en él la delantera Europa y Estados Unidos, las naciones de Hispanoamérica, incluido México, "están bastante atrasadas", aclaraba. ${ }^{108}$

Ahora bien, en lo moral, ¿ progreso hacia dónde?: hacia los derechos del hombre, al menos cuatro: "libertad, propiedad, seguridad e igualdad", ${ }^{109}$ que eran elementos establecidos por Dios mismo en la naturaleza humana: al final, aunque no se ocupó, hasta donde sabemos, en exponerlo con todo detalle, la Providencia y el Progreso estaban relacionados. El dilema aquí es que, casi sobra decirlo, en el esquema de Rivera la religión cristiana era el progreso lento, mientras la civilización moderna el progreso radical. De ahí que pudiera citar a su historiador preferido, César Cantú: "Cristo hace reformas, no revoluciones". ${ }^{110}$ En cambio, la revolución francesa, y por ello no podía ser realmente condenada, era el progreso radical, natural, en su mejor expresión, y la religión no podía sino acompañar a la naturaleza sin jamás oprimirla. Tal, pues, en el inicio de la última década de su vida, el discurso conciliador de Agustín Rivera y Sanromán.

\footnotetext{
106 Rivera, El progreso lento y el radical, p. 1.

107 Rivera, El progreso lento y el radical, pp. 1 y 6.

108 Rivera, El progreso lento y el radical, pp. 2-3.

109 Rivera, El progreso lento y el radical, p. 8.

110 Rivera, El progreso lento y el radical, p. 22.
} 
Como puede advertirse, los autores franceses lo mismo contribuyeron a la formación del doctor Agustín Rivera y Sanromán, que dieron motivo a reflexiones y sobre todo a debates. Claramente nuestro autor prefería a galicanos que a ultramontanos, pero nunca se identificó con claridad con esas categorías. De hecho, más bien su vida y trayectoria nos llevan a reflexionar sobre las categorías para definir al clero del siglo xIx: por su creencia en el progreso y en los derechos, tenía bien ganado el calificativo de liberal; mas ya lo han notado algunos autores recientemente, su cultura clásica más bien lo hubiera acercado a personalidades importantes del conservadurismo mexicano. ${ }^{111}$ Lector asiduo de autores ilustrados, él mismo muchas veces gustaba de identificarse como autor anacrónico, empero su fidelidad a los jesuitas nos hace difícil tenerlo propiamente como un ilustrado. Asimismo, fue crítico del ultramontanismo, incluso de sus manifestaciones de piedad, pero no del papa ni del dogma de la infalibilidad pontificia, ni de otras célebres decisiones de Pío IX o de León XIII. Es, pues, complicado encontrar los términos adecuados para describir esta trayectoria, que además es muy claro que, siendo original, tampoco es de ruptura. Si una virtud tuvo Rivera fueron sus amplios vínculos, dentro y fuera del clero; de hecho, es claro también su orgullo por una cultura que comparte con prelados y presbíteros, y que deseaba heredar a los jóvenes. Con ellos comparte sus escritos, como los 11 que hemos examinado aquí y que al menos nos orientan en su larga trayectoria hacia el principio fundamental de la conciliación en la tradición.

111 Véase OrTiz, "El humanismo conservador”. 
Éste se evidencia ya en las citas eclécticas de Rivera, a cada paso lo hemos detallado; los números resultan interesantes: filósofos clásicos son citados prácticamente en la misma proporción que autores modernos; grandes representantes de movimientos religiosos enfrentados se encuentran juntos casi al mismo nivel en la obra de nuestro autor. Rivera construyó, gracias a esas lecturas, en que tenían su parte fundamental - más no exclusiva - los textos franceses, una antropología católica que insistía en la conciliación entre la naturaleza humana (capaz de alcanzar el limbo por sí misma) y la gracia divina (que abría las puertas del Cielo). Él la estimó siempre como la verdadera tradición católica, la que era capaz asimismo de conciliar "clásicos cristianos" y "clásicos paganos”, y la que había que defender, incluso de publicistas católicos como monseñor Gaume, "purista” peligroso por romper la conciliación del lado de lo religioso. Ello no significaba que fuera complaciente con la cultura moderna, también se esforzó por moderar la secularización, en particular en el campo de la cultura; de ahí sus críticas a los autores románticos, los que desalojaban lo moral de los criterios del gusto estético, ahí donde Rivera también esperaba la conciliación entre arte y religión a través del "retrato de caracteres”. En fin, conciliación entre progreso radical y progreso lento, entre el ritmo de la religión y el de la civilización moderna.

\section{REFERENCIAS}

Aubert, Robert, "La géographie ecclésiologique au Xix siècle", en Revue des Sciences Religieuses, 34: 2-4 (1960), pp. 11-55. 
Baschet, Jérôme, La civilización feudal. Europa del año mil a la colonización de América, México, Fondo de Cultura Económica, 2009.

Boutry, Philippe, Prêtres et paroisses an pays du curé d'Ars, París, Éditions du Cerf, 1986.

BRUnet, Manon, "Les réseaux gaumistes constitutifs du réseau littéraire québécois du XIx ${ }^{e}$ siècle”, en Globe. Revue internationale d'études québécoises, 7:1 (2004), pp. 147-180.

Connaughton, Brian, “Agustín Rivera, Feijoo y la epopeya nacional mexicana”, en Olivera y Meza (coords.), 2009, pp. 13-39.

Connaughton, Brian, Entre la voz de Dios y el llamado de la patria, México, Fondo de Cultura Económica, Universidad Autónoma Metropolitana-Iztapalapa, 2010.

Cottret, Monique, Jansénismes et Lumières. Pour un autre XVIII siècle, París, Albin Michel, 1998.

Cuchet, Guillaume, Le crépuscule du Purgatoire, París, Armand Colin, 2005.

Elías, Norbert, La sociedad cortesana, México, Fondo de Cultura Económica, 2012.

Frey de Neuville, Charles, Sermons, París y Lyon, L.N. Moutard y J.G. Merigot, P. Bruyset-Ponthus editores, 1777.

García Jurado, Francisco, "La Iglesia Católica contra la enseñanza de los clásicos en el siglo xix: el abate Gaume y su repercusión en España. Una página poco conocida de la educación clásica”, en Estudios Clásicos, 125 (2004), pp. 65-81.

García Ugarte, Marta Eugenia, Poder político y religioso. México, siglo XIX, México, Miguel Ángel Porrúa, Universidad Nacional Autónoma de México, Instituto Mexicano de Doctrina Social Cristiana, Cámara de Diputados LXI Legislatura, 2010. 
HÉRISson, Arthur, "Louis Veuillot, L'Univers et l'intervention des laïcs dans les affaires de l'Église de France au milieu du XIX siècle", en Revue de l'Histoire de l'Église de France, 100 (2014), pp. 333-354.

LagréE, Michel, Religion et modernité: France, XIX-XXe siècles, Rennes, Presses Universitaires de Rennes, 2002.

Lalouette, Jaqueline, La séparation des Églises et de l'État: genèse et développement d'une idée, 1789-1905, París, Seuil, 2005.

Maire, Catherine, De la cause de Dieu à la cause de la nation: le jansénisme au XVIII ${ }^{e}$ siècle, París, Gallimard, 1998.

Moulinet, Daniel, Les classiques païens dans les collèges catholiques? Le combat de monseigneur Gaume, 1802-1879, París, Éditions du Cerf, 1995.

Muñoz Moreno, Rafael, Rasgos biográficos del Sr. Dr. D. Agustín Rivera y Sanromán, Lagos de Moreno, Imprenta López Arce, 1906.

Nicolás, Augusto, Estudios filosóficos sobre el cristianismo, Madrid, La Publicidad, 1854, t. II.

Nicolas, Auguste, Études philosophiques sur le christianisme, París, Librairie de Piété et d'Éducation d'Auguste Vaton, 1852, t. III.

Olivera, Luis Humberto y Rocío Meza (coords.), Archivo Agustín Rivera y Sanromán de la Biblioteca Nacional, 1547-1916, México, Universidad Nacional Autónoma de México, El Colegio de Jalisco, 2009 , t. III.

Ortiz Dávila, Juan Pablo, "El humanismo conservador: letras clásicas y política a mediados del siglo XIX”, en Signos históricos, 31 (2014), pp. 38-87.

Rivera, Agustín, Bodas de oro de Agustín Rivera como escritor público celebradas el día 11 de mayo de 1897, Guadalajara, Tipografía de la Escuela de Artes, 1897. 
Rivera, Agustín, Concordancia de la razón y la fe, San Juan de los Lagos, Tipografía de José Martín, 1876.

Rivera, Agustín, Descripción de un cuadro de veinte edificios, San Juan de los Lagos, Tipografía de José Martín y Hermosillo, 1883.

Rivera, Agustín, El Cempazúchil, Lagos de Moreno, Ausencio López Arce impresor, 1891.

Rivera, Agustín, El progreso lento y el radical en la destrucción de la esclavitud en las naciones cristianas, Lagos de Moreno, Ausencio López Arce e hijo impresores, 1897.

Rivera, Agustín, Ensayo sobre la enseñanza de los idiomas latino y griego y de las bellas letras por los clásicos paganos a los jóvenes y a los niños escrito en Lagos en 1880, San Juan de los Lagos, Tipografía de José Martín y Hermosillo, 1881-1889.

Rivera, Agustín, Inscripciones colocadas en las paredes del Liceo de Lagos presentadas por el Dr. D. Agustín Rivera, catedrático de Historia en el mismo establecimiento, sin pie de imprenta, 1869.

Rivera, Agustín, La pobre humanidad a través de la púrpura, el cetro, el libro, el laurel y el crucifijo, o sean Pensamientos muy filosóficos del sermón de Carlos Neuville de la Compañia de Jesús y orador de Luis $X V$ sobre el Genio, escogidos y anotados, Lagos de Moreno, Ausencio López Arce impresor, 1893.

Rivera, Agustín, Los dos estudiosos a lo rancio, o sea Diálogo crítico, San Juan de los Lagos, Tipografía de Vicente Veloz, 1882.

Rivera, Agustín, Miscelánea selecta o sea colección de sentencias, pensamientos, trozos y noticias escogidos de muchos autores, San Juan de los Lagos, Tipografía de Vicente Veloz a cargo de A. López Arce, 1880-1889.

Rivera, Agustín, Paralelo entre el Contrato social de Juan Jacobo Roussean y el sermón del ilustrísimo Sr. D. Antonio Joaquín Pérez, obispo de Puebla, predicado en el púlpito de su catedral en pro del Plan 
de Iguala el día 5 de agosto de 1821, delante de Iturbide, Lagos de Moreno, Ausencio López Arce impresor, 1894.

Rivera, Agustín, Tres artículos de Agustín Rivera sobre el elogio que en su arenga del 27 de octubre próximo pasado hizo de los Principios proclamados por la Revolución Francesa de 1789, Lagos de Moreno, Ausencio López Arce impresor, 1891.

Serrano, Sol, ¿Qué hacer con Dios en la república? Política y secularización en Chile (1845-1885), Santiago de Chile, Fondo de Cultura Económica, 2008.

Toro, Alfonso y Juan Bautista Íguiniz, El Dr. Dn. Agustín Rivera y Sanromán, México, Academia Mexicana de la Historia, 1927.

Valverde Téllez, Emeterio, “El presbítero Dr. D. Agustín Rivera”, en Crítica filosófica o Estudio bibliográfico y crítico de las obras de filosofía escritas, traducidas o publicadas en México desde el siglo XVI hasta nuestros dias (1904), en http://www.filosofia.org/aut/001/ev190421. htm\#kp254 Consultado el 6 de marzo de 2015.

Van Kley, Dale, Les origines religieuses de la Révolution Française (1560-1791), París, Seuil, 2006.

VV.AA., Les fondations nationales dans la Rome pontificale. Actes du colloque de Rome (16-19 mai 1978), Roma, École Française de Rome, 1981.

Ventura, Joaquín, La escuela de los milagros. Homilías sobre las principales obras del poder y de la gracia de Jesucristo, hijo de Dios y salvador del mundo, predicadas en la Sacrosanta Basílica Vaticana, t. I, Madrid, Lima, La Habana, Valparaíso, Librería Universal de Leocadio López, Librería de los Señores Calleja, Sres. Charlain y Fernández, Librería de los Sres. Tornero y Compañía, 1857.

Wenger, Antoine, "La querelle des ultramontains et des gallicans à Rome à propos du Ver rongeur de Monsieur Gaume (1851-1853)", en VV.AA., 1981, pp. 821-849. 